\title{
La alquimia y los sacerdotes mineros en el virreinato del Perú en el siglo XVII
}

L'alchimie et les prêtres miniers dans la vice-royaute du Pérou au XVIIeme siècle Alchemy and priests envolved in mining projects in the viceroyalty of Peru in the $17^{\text {th }}$ century

\section{Carmen Salazar-Soler}

\section{OpenEdition}

Journals

\section{Edición electrónica}

URL: http://journals.openedition.org/bifea/7085

DOI: $10.4000 /$ bifea.7085

ISSN: 2076-5827

\section{Editor}

Institut Français d'Études Andines

\section{Edición impresa}

Fecha de publicación: 1 diciembre 2001

Paginación: 475-499

ISSN: 0303-7495

\section{Referencia electrónica}

Carmen Salazar-Soler, « La alquimia y los sacerdotes mineros en el virreinato del Perú en el siglo XVII », Bulletin de I'Institut français d'études andines [En línea], 30 (3) | 2001, Publicado el 08 diciembre 2001, consultado el 10 diciembre 2020. URL : http://journals.openedition.org/bifea/7085; DOI : https://doi.org/10.4000/bifea.7085

\section{(@) $\odot \Theta$}

Les contenus du Bulletin de l'Institut français d'études andines sont mis à disposition selon les termes de la licence Creative Commons Attribution - Pas d'Utilisation Commerciale - Pas de Modification 4.0 International. 


\title{
LA ALQUIMIA Y LOS SACERDOTES MINEROS EN EL VIRREINATO DEL PERÚ EN EL SIGLO XVII
}

\author{
Carmen SALAZAR-SOLER*
}

\section{Resumen}

A través del examen de los manuales mineralógicos y metalúrgicos de Alonso Barba, sacerdote seglar residente en Potosí y de Miguel de Monsalve, dominico residente en Lima, este trabajo se propone analizar un conjunto de ideas alquímicas que circularon en el Perú en el siglo XVII, estudiar sus modalidades de traslación e implantación en este virreinato. De manera más general este estudio pretende reflexionar sobre la construcción de un corpus de saberes mineros en el Perú colonial y sobre sus mecanismos de transmisión.

Palabras claves: Alquimia, historia de ciencias, Huancavelica, minería, Potosí.

\section{L'ALCHIMIE ET LES PRÊTRES MINIERS DANS LA VICE-ROYAUTÉ DU PÉROU AU XVIIÈME SIÈCLE}

\section{Résumé}

À travers l'examen des manuels de minéralogie et de métallurgie de Alonso Barba, curé résidant à Potosí et de Miguel de Monsalve, dominicain résidant à Lima, ce travail se propose d'analyser un ensemble d'idées alchimiques qui circulèrent au Pérou pendant le XVIIème siècle, et les modalités de leur transfert et d'implantation dans le vice-royaume. De manière plus générale, cette étude se veut une contribution à la réflexion sur la construction d'un corpus de savoirs miniers dans le Pérou colonial et sur les mécanismes de leur transmission.

Mots clés : Alchimie, histoire des sciences, Huancavelica, activité minière, Potosí.

\section{ALCHEMY AND PRIESTS ENVOLVED IN MINING PROJECTS IN THE VICEROYALTY OF PERU IN THE $17^{\mathrm{TH}}$ CENTURY}

\begin{abstract}
Through the study of the manuals of mineralogy and metallurgy written by Alonso Barba, a lay priest residing in Potosi, and Miguel de Monsalve, a Dominican residing in Lima, this article sets out to analyse a series of ideas concerning alchemy which circulated in Peru in the $17^{\text {th }}$ century and to study the ways in which they were introduced and developed in the viceroyalty. In more general terms, the study aims at analysing the establishment of a corpus of mining knowledge in colonial Peru and the mechanisms of its transmission.
\end{abstract}

Key words: Alchemy, history of science, Huancavelica, mining, Potosi.

${ }^{*}$ CERMA/UMR 8565, EHESS, 54, Bd. Raspail, 75006 - Paris. E-mail: carmen.salazarsoler@ehess.fr 
El presente artículo está centrado en el examen y comparación de las obras y en particular de las ideas de dos religiosos mineros del virreinato del Perú en el siglo XVII: se trata de Alvaro Alonso Barba, sacerdote seglar español residente en Potosí, autor del Arte de los metales (1640) (1) y del dominico Miguel de Monsalve, predicador general de la orden, residente en Lima, cuyo ámbito de acción en lo que concierne la minería fueron Potosí y Huancavelica. Ambos comparten muchos rasgos: además de ser eclesiásticos, son autores de tratados de minería y metalurgia, proponen nuevos métodos de beneficio de minerales de plata (Alonso Barba presenta el famoso método de cazos; Monsalve propone un nuevo método para beneficiar con mayor rendimiento los minerales negrillos) o de fundición (Monsalve: Nuevo modo y traza de hornos y de fundición de metales de azogue), pero sobre todo y éste será el tema que nos ocupará, comparten algunas ideas sobre el génesis de los metales, en particular ideas alquímicas pero en la mayoría de los casos con raíces en la Antigüedad, que como intentaremos demostrar, circularon en España desde el siglo IX y llegaron al Perú en el siglo XVI. El propósito de este trabajo es analizar este cuerpo de ideas relativas a la minería que circularon en el siglo XVII, estudiar sus modalidades de traslación y de implantación en el Perú. En este sentido, este artículo forma parte de un trabajo de investigación más amplio sobre los mecanismos de transmisión de conocimientos en la minería andina.

El Arte de los metales, como ya lo hemos evocado en otro trabajo, es un tratado construido según el modelo doxográfico griego. Está dividido en dos partes. La primera es teórica y en ella se exponen y discuten diversas teorías concernientes a la generación de los metales, de los minerales y de los yacimientos metalíferos; el autor presenta además su propia teoría en la materia para la región de Potosí. En la segunda parte se abordan los temas prácticos; el autor propone un nuevo método de beneficio para minerales de plata: el método de cazos (2). En el caso de Monsalve estas dos partes no se encuentran reunidas en una sola obra, sino que las encontramos como dos documentos separados:

- Tratado y discursos echos por el padre frai Miguel de Monsalve, predicador general de la Orden de predicadores aserca de la generasion del azogue, y cómo procede del asufre, y de cómo el azogue es la quincta essensia del azufre, dirigidos al mui illustre señor el doctor Juan de Solorsano Pereira del consejo de su magestad y su oidor en la Real audiensia de los Reyes, y gobernador de Guancabelica por el rey Nuestro Señor; y

- Cartas y dibujos de Fr... sobre un nuevo modo y traza de hornos y fundición de metales de azogue (1617) (3).

(1) El título completo del tratado es: El arte de los metales, en que se enseña el verdadero beneficio de los de oro, y plata con azogue. El modo de fundirlos todos y como se han de refinar; y apartar unos de otros [1640]. En este trabajo utilizaremos la edición del CSIC, Madrid, 1992. Sobre la vida y obra del autor consultar el estudio de Barnadas (1986).

(2) Hemos abordado el análisis de la primera parte del Arte de los metales en un trabajo anterior: Salazar-Soler, 1997.

(3) En este artículo utilizaremos solamente el primer documento: Biblioteca Nacional de Madrid, J57, fols. 557-561, cuya transcripción presentamos al final del presente trabajo. Agradezco a J. C. Estenssoro por haberme indicado la existencia de estos textos. 
En ambos casos limitaremos nuestro trabajo a la primera parte, la cual podríamos llamar teórica.

La comparación nos permitirá abordar varias ideas sobre el génesis de los metales y en particular aquellas sobre la participación del azufre y del mercurio en tanto principios de la formación de los metales, la acción necesaria del firmamento como generador general y la influencia de los astros en el génesis de los metales. Si bien la mayoría de estas ideas están presentes en los dos autores analizados, veremos cómo las explicaciones sobre el génesis de los minerales construidas a partir de ellas presentan diferencias de composición. Se trata de combinaciones propias hechas a base de fragmentos provenientes de tradiciones culturales diferentes: ideas alquímicas cuyas raíces encontramos en la Antigüedad griega o latina.

El interés por el examen de la difusión de ideas alquímicas no se reduce a la historia de las ciencias, sino que su estudio recubre el campo de la historia cultural y religiosa. Basta recordar los tres objetivos principales de la alquimia: la obra del alquimista es esencialmente un trabajo de purificación, que consiste en fabricar en el laboratorio lo que la naturaleza no ha sabido realizar perfectamente; el segundo objetivo es obtener un elixir, es decir, un remedio universal tanto para curar enfermedades como para prolongar la vida humana y en tercer lugar se trata de adquirir un conocimiento de todas las cosas y de toda la naturaleza. En muchas de las obras alquímicas, el arte es presentado no solamente como una ciencia cuyo fin es enseñar la transmutación metálica, sino una ciencia verdadera y sólida, que enseñe a conocer la esencia de todas las cosas. La alquimia es considerada así como una filosofía natural, puesto que muestra la base, el fundamento y la raíz de todas las cosas creadas. Así lo demuestran las principales ideas alquímicas, algunas de las cuales trataremos en el presente trabajo:

- la solidaridad entre los diferentes reinos de la naturaleza;

- la correspondencia entre cielo y tierra;

-la semilla que se encuentra en todos los cuerpos y que constituye la substancia (unidad de la materia) (4).

Por último estamos también interesados en subrayar cómo estos sacerdotes se sirven de la alquimia para entender el proceso natural; se usa una tradición heterodoxa para estudiar la naturaleza, para revertir el orden natural. En ciertos casos, no necesariamente los tratados aquí, se intentó sustituir a la naturaleza para alcanzar un fin no lícito: la vanidad de la producción.

\section{LA UNIDAD DE LA MATERIA}

En el capítulo XIX de su tratado Alonso Barba expone algunas de sus ideas acerca de la generación de los metales, sostiene que:

"Los que se han alzado con el nombre de filósofos, por entender en el conocimiento de las causas dejando la materia prima por principio remotísimo de los metales, como lo es de todas las demás cosas corporalistas de este

(4) Para los objetivos de la alquimia consultar Joly, 1992: 52-54. 
mundo, señalan otra, aunque también remota, que es cierta exhalación húmeda y untuosa por una parte, y por otra una porción de tierra viscosa y crusa, de cuya junta resulta una materia, que no sólo es de los metales, sino también de las piedras, y si tiene más de humedad pingue se convierte en metal. Así lo sienten Platón, Aristóteles y sus secuaces" (Alonso Barba, 1992[1640], libro I, cap. XVII: 33).

Como Alonso Barba se encarga de señalar, encontramos en su explicación sobre la generación de los metales rastros de las teorías de la Antigüedad, así como también de la alquimia. Veamos las raíces de estas ideas.

Aristóteles expone sus ideas acerca de la formación y la naturaleza de los metales en la parte final del tercer libro de las Metereológicas. Para él, la base de la explicación es la misma que encontramos en Platón, es decir, la física de los cuatro elementos y el origen de los metales en la humedad. Pero Aristóteles integra la formación de los metales dentro de la teoría de la doble exhalación, teoría meteorológica.

Este filósofo dice que en el universo, los cuatro elementos (tierra, agua, aire y fuego) están superpuestos siguiendo ese orden. Cuando el sol calienta la tierra, se produce una doble exhalación: aquella que viene de lo húmedo continúa en la tierra, es húmeda, de la naturaleza del vapor, es potencialmente agua, mientras que la que procede de la tierra misma es seca, muy inflamable, de la naturaleza del humo. Sobre la superficie de la tierra estos dos tipos de exhalaciones dan lugar a fenómenos diferentes: la exhalación seca causa los fuegos celestes, las auroras boreales, la vía láctea... y la exhalación húmeda es la causa de la lluvia, las nubes, la neblina, la nieve... pero cuando estas exhalaciones se encuentran encerradas por las partículas de la tierra, causan dos cuerpos diferentes: los minerales y los metales. La exhalación seca es aquélla que quemando produce todos los minerales no metálicos, como las especies de piedras no fusibles, el ocre, el vermellón, el azufre y los otros cuerpos del mismo género. La exhalación vaporosa, por su lado, es la causa de todos los cuerpos que se extraen de las minas, ya sea fusibles o maleables, como el fierro, el oro o el cobre. Todos son producidos por la exhalación vaporosa que, encerrada en el suelo y especialmente en la piedra, se comprime en una sola masa por la sequedad y se condensa.

Los metales se forman entonces, por la condensación de la exhalación húmeda (vaporosa), comprimida por la sequedad del medio ambiente y solidificada por el frío de ese medio. La compresión por el medio explica la dureza de los metales y la presencia de agua el hecho de que muchos de los metales sean fusibles. Pero la exhalación húmeda no da cuenta de todo, Aristóteles reconoce la diferencia entre los metales. Unos son fusibles, otros son tan sólo maleables y otros son susceptibles al fuego.

La exhalación vaporosa dice Aristóteles, pasa al estado sólido sin pasar por el estado líquido. Antes de convertirse en agua, se fija al estado de metal. De la congelación de estas exhalaciones resultan mezclas en las que la tierra interviene en proporciones variables. Se establece así, sobre esta base, una escala de diferentes metales según la proporción de agua y de tierra.

Alonso Barba recoge esta teoría de la doble exhalación en la generación de los metales. Así en el capítulo XII del Arte de los metales dice: 
"Los alquimistas (odioso nombre por la multitud de ignorantes que con sus embustes lo han desacreditado) con más profunda y práctica Filosophia, haciendo anatomia de los mixtos de naturaleza, reduciéndolos a sus primeros principios, discurren en la materia de los metales desta manera. El Sol dicen, y todos los demás astros, con su luz ó propia, ó prestada, rodeando continuamente la tierra, la calientan y penetran por sus venas con la sutileza de sus rayos. Quemada así por largo tiempo, se convierte también en otra sustancia también térrea, como vemos que la leña, y piedras se convierten en ceniza y cal. Esta tierra así quemada, mezclada y cocida con el agua, se transmuta en otra cierta especie, que contiene en sí algo de la substancia de sal y alumbre [...]. Esta primera materia, o fundamento de la generación de los metales, es el vitriolo. Facilita el creerlo así, el ver que todos ellos pueden por arte bolver a convertirse en él [...].

Este vitriolo, por el calor del fuego subterráneo y atracción del celeste, echa dos humos, o vapores, el uno térreo sutil, y untuoso, y algo digesto, que los philosophos llaman azufre, porque en las calidades se le parece: el otro húmedo, aqueo, viscoso, y mezclado de térreo sutil, que es la materia próxima del azogue. Estas dos vaporosas exhalaciones se hallan en la tierra libre y anchurosa, salidas y levantadas á la región del ayre, se convierten en cometas nubes, nieves, granizos, rayos y demás cosas que en ella se engendra, y aparecen.

Pero si el lugar fuere angosto y tan apretado, que las dichas dos exhalaciones humosas no tengan salida, buscándola por entre los resquicios y hendeduras de las peñas o lugar mineral, se engruesan y convierten en lo que llaman medios metales [...].

Si subiendo estos vapores, se le opone alguna piedra tan dura, que no puede penetrarla, se convierten en perpetuos manantiales de agua [...]. Pero, si transpasando las peñas hallan estos dos jugos, la margajita o azufre lavado, casi fijo [...] mezclándose con él, y por cocimiento sucesivo, se espesa en la mina, se endurece y hace metal. Este discurso es el de Bracesco, en la explicación de los Libros de Getro. Los más afirman ser la materia inmediata de los metales el Azogue, y Azufre, que la variedad de proporción en su mezcla, y de su mayor, ó menor purificación y eximiento, resulta la diferencia que en los metales se ve" (Alonso Barba, 1992[1640], libro I, cap. XVIII: 34-35).

La idea sobre la unidad de la materia, que aparece en el texto de Alonso Barba, constituye uno de los postulados esenciales de la teoría alquímica. La materia es una, decían los alquimistas, pero ella puede tomar diversas formas y bajo formas nuevas combinarse ella misma y producir cuerpos nuevos en cantidad indefinida. Estos filósofos llamaron a esta materia primera con diversos nombres: semilla, caos, substancia universal, absoluto, etc (Hutin, 1951: 69). Esta teoría no fue, sin embargo, una invención de la alquimia, sino que Platón ya había abordado esta noción de la materia primera, común a todos los cuerpos y apta a tomar todas las formas. Pero fueron los alquimistas quienes la desarrollaron. 
Encontramos también en Miguel de Monsalve esta idea de la unidad de la materia. En el encabezado de su propuesta dice:

“Conosiendo mui illustre señor el gran deseo de vuestra merced aserca del aprobechamiento real como tan leal vasallo de su magestad, quise haser algunos discursos aserca de la generasion del azogue y producion de la quincta essensia del mismo asufre, el qual se verá por mis rasones, ser el azogue la quincta essensia i virctud del azufre como se verá por la experiensia queriendola haser como la embio a vuestra merced, de la qual se conosera que es sierto y verdadero, y ser engendrado y producido (mediante el fuego) del asufre, y que de [é]l, como de causa universal, resiben los demas metales ser, como primera materia de su generasion [...]" (Monsalve, 1617: 557).

Según afirma García Font en su libro sobre la Historia de la Alquimia en España (1976), antiguamente se concebía la materia en función de cuatro elementos opuestos que presidían todos los cambios o todas las transformaciones: el calor, el frío, lo seco y lo húmedo. Estas cualidades no existían al estado puro, sino como modalidades de una fuerza única que se combinaban de manera distinta en el mundo material. Las manifestaciones de esta fuerza eran: tierra, agua, aire y fuego. Cada uno de esos elementos eran el resultado de la acción de dos cualidades de la materia. Así si la materia era concebida caliente y seca, daba lugar o formaba el fuego elemental, cuando aparecía seca y fría, se llamaba tierra; cuando se mostraba fría y húmeda, producía el agua, y el aire cuando combinaba el calor y lo húmedo. Pero la tierra no era concebida de manera unívoca. Se hablaba de numerosas tierras según la proporción en que se se combinaban las cualidades originales. Se aludía a tierras cercanas al fuego o cercanas al agua. Lo mismo sucedía con los otros elementos (García Font, 1976: 131).

\section{LOS DOS ELEMENTOS}

A pesar de esta teoría sobre la unidad de la materia, para los alquimistas son dos los elementos constitutivos de los metales: el azufre y el mercurio. La idea sobre la participación del azufre y el mercurio, en tanto principios en la formación de los metales tomó cuerpo en los tratados elaborados por los alquimistas árabes en la segunda mitad del siglo IX. Como sabemos, la alquimia medieval se expandió en Europa Occidental en el siglo XII a través de España, en donde aparecieron las primeras traducciones latinas de las obras de los alquimistas árabes. Si bien estas ideas formaban parte del cuerpo teórico de los alquimistas, podemos encontrar sus raíces en la teoría de los cuatro elementos de los filósofos de la Antigüedad y en la de las dos exhalaciones de Aristóteles.

B. Joly afirma, citando a Ganzemüller, que en el origen de estas teorías se encuentran consideraciones resultando de las técnicas metalúrgicas. En efecto, la mayor parte de los minerales contienen azufre, el cual puede ser aislado por distilación. Esto es particularmente cierto en el caso del mineral de mercurio, el cinabrio, cuyo tratamiento metalúrgico hace aparecer fácilmente el azufre y el mercurio. Esta operación ha podido ser considerada como el prototipo de la manifestación de los principios 
constitutivos de los metales: todos despiden azufre, mientras que el calor los vuelve líquidos, como el mercurio (Joly, 1992: 125-127).

Ganzenmüller dice que fueron los alquimistas árabes quienes teorizaron estas observaciones y quienes sistematizaron el análisis teórico de los metales en azufre y mercurio. Según Joly, esta teoría de la constitución de los metales fue transmitida del mundo árabe al occidente latino a través de la traducción de De congelatione et conglutione lapidum de Avicena. Luego, la doctrina fue desarrollada en el Liber Trium Verborum de Kalid, el Tractatulus de Avicena, la Summa perfectionnis atribuida a Geber y el Perfecto magisterio, este último atribuido entonces a Aristóteles pero que según Joly es sin duda la obra de un contemporáneo de Avicena. Todos los metales son presentados como el resultado de una mezcla de azufres y mercurios de calidades y colores diferentes, lo que explica a la vez su multiplicidad y su imperfección. Sólo el oro y la plata están compuestos de un azufre y mercurio puros (Joly, 1992: 271).

Podemos resumir la idea que circulaba entre los alquimistas de la siguiente manera: en la generación de los metales es necesaria la acción de un elemento generador y la presencia de una cosa sumisa, una materia que sea capaz de recibir la acción generadora. De una parte, el generador general es el firmamento con su movimiento; de la otra, la tierra libera emanaciones, azufre y mercurio que se unen bajo la acción del firmamento para dar origen a los metales. En esta unión el azufre se comporta como la semilla masculina, el padre, el espíritu, y el mercurio como la semilla femenina o como la madre en el momento de la concepción de un niño. Estos principios no designaban a los elementos en el sentido estricto, sino más bien a hipóstasis de ciertas propiedades inherentes a diferentes materias. El azufre representaba el principio de combustibilidad, el mercurio los de volatización, liquidez y fusibilidad.

Estas ideas perduraron hasta los siglos XV y XVI. En el siglo XVI, Paracelso agrega a estos dos elementos azufre y mercurio, un tercero: la sal, principio-propiedad que materializaba la fijación del fuego, la solubilidad y las estructuras cristalinas.

Alonso Barba, fiel a la tradición árabe española, no duda en seguir la concepción anterior a Paracelso, y así en el capítulo XIX del Libro I de su obra, defiende la opinión según la cual el azogue y el azufre son la materia inicial en la generación de los metales:

"No hay cosa más experimentada entre los que tratan de metales, que la mezcla ordinaria que tienen de azufre, y su abundancia en los minerales no es pequeña señal de su riqueza [...]. En el azogue pasa lo propio, aunque menos advertido, por ser cosa que en los metales crudos no está tan sujeta a la vista, ni perdiéndose el humo en los que se queman, se dejan conocer el olfato, como el azufre; pero bien experimentados son sus efectos en los que con poco recato asisten a los humos de las fundiciones [...]" (Alonso Barba, 1992[1640], libro I, cap. XIX: 36).

Alude también a esta idea al abordar la descripción y definición del azufre:

"Llámanlo los que tratan de la filosofía secreta de los metales, semilla masculina y primer agente de la naturaleza en su generación: y dicen que la diferencia que entre unos y otros hay, proviene de su varia purificación y mixtura con el azogue [...]" (Alonso Barba, 1992[1640], libro I, cap. $\mathrm{X}: 19$ ). 
En el caso del padre Miguel de Monsalve esta teoría de los dos elementos aparece de una forma particular: el

"ser el azogue la quincta essencia i virctud del azufre como se verá por la experiensia [...], de la qual se conosera que es sierto y verdadero, y ser engendrado y producido (mediante el fuego) del asufre [...]".

Veamos en detalle lo que dice Monsalve:

“... El qual para avello /558r/ de engendrar el sol como poderosso en la generasion crio primero el asufre escogiendo la parte de tierra más bien dispuesta y ésta para engendrar de ella el asufre quasi de su misma especie, en lo que toca a su calor este asufre lo engendró de lo más perfecto y puro de la tierra, aunque como siempre [testado: do] el planeta anda acompañado de los astros instantaneamente que el sol engendra el asufre, los demas astros como teniendo invidia engendran ellos como el mismo [testado: sus malesas] asufre sus malesas [...]. Y asi él es que a engendrado de lo más graso de la tierra el asufre como tengo dicho, y con el calor interior de la tierra y con sus rayos penetrantes de su calor viene a ensender 1559r/ este asufre y yendose ensendiendose asta el lugar donde llegó su potensia este asufre va quemandose y abrasandose sin tener respirasion (porque si la tuviera todo se fuera en humo y de ninguna manera se quajara [interlineado: genero de; testado: quemado] azogue antes quedara todo el metal consumido quemado sin ninguna substansia ni ser de cosa alguna que el sol criase ni engendrase, pero como se serro la puerta a esta generasion no teniendo respirasion, fue el fuego quemando el asufre y piedras y lugares donde con la fuersa del fuego alcansaba y este humo deste asufre metiendose en los poros de la tierra y piedras, alli se congelaba y transmutaba en azogue, y siendo mucho el cosimiento del asufre esta fuersa aver mucho que quemar, y durar mucho tiempo de donde con el grande inçendio se quemó mucho el azogue, el qual por la mucha violensia del fuego lo quemó y deshiso, y no sólo esto, pero convirtió el azogue en la misma color del fuego que es bermillon, quemando, abrasando y recosiendolo en lo interior de la tierra vino a arronjar de la grasa del metal gran suma de espuma, que al pareser parece azeite y no lo es sino grasa del asufre" (Monsalve, 1617: fols. 558r-559).

Para analizar el texto de Monsalve, comparémoslo con el de otro alquimista del siglo XVII, Pierre-Jean Fabre, médico de Castelnaudary y autor de Manuscriptum ad Fridericum (1690), pues la relación azufre y mercurio se presenta en los dos autores de manera muy similar. Fabre nos dice que no podemos explicar lo que es el mercurio de los Filósofos, sin explicar al mismo tiempo lo que es el azufre. Éstos constituyen un sólo y mismo sujeto, y no pueden ser separados. En efecto, lo que es caliente e ígneo en el mercurio, es el azufre, mientras que lo que es húmedo es mercurio. De tal manera que el mercurio posee en él un azufre nativo apropiado que permite a su húmedad de coagularse en oro. El azufre de los Filósofos consiste entonces en ese calor radical que reside en el mercurio y en todas las cosas. Es gracias a su acción que todas las cosas maduran y son llevadas a la perfección suprema y acabada. De ahí viene que sea por el azufre que el mercurio de los Filósofos alcanza su madurez y perfección. 
"Queda entonces que el Azufre de los Filósofos es el calor natural del Mercurio, no se separan nunca y es solamente por él que el Mercurio alcanza su madurez y su perfección y se transforma en oro" (Fabre, 1992[1690], cap. IX: 159).

Así el azufre reside en el mercurio, o si se prefiere el mercurio posee en él azufre. Joly señala que esta jerarquía no corresponde, sin embargo, a una sugerida en capítulos anteriores por Fabre, quien en el capítulo $\mathrm{V}$ de su obra presenta los tres principios como diferentes aspectos de la substancia metálica, estableciendo un orden de producción que sigue la manera cómo las diferentes cualidades engendran los elementos en la filosofía antigua. Así la sal engendra el mercurio, que a su vez engendra el azufre (reconocemos los tres elementos de Paracelso). Por el contrario en el capítulo VII de la obra, es la divina trinidad que sirve de modelo, afirmando así que es el azufre que engendra la sal, que a su vez engendra el mercurio. En el capítulo IX, que hemos citado, el mercurio parece tener un papel primordial, pues es el sujeto del cual el azufre es finalmente una cualidad.

Joly dice que ésta es una de las paradojas habituales que son expresiones de la complejidad de la substancia metálica, cuyos diferentes principios constitutivos manifiestan su prevalencia según el punto de vista que adopte el análisis. Si el mercurio es presentado como primordial, es porque designa la unidad absoluta de los tres principios, en tanto que es una semilla que circula a través de todas las cosas. Pero también se puede afirmar que el azufre no le pertenece de manera accesoria sino esencial, pues sin él el mercurio no poseería su perfección, lo que significa que no sería un principio. Azufre y mercurio entonces poseen, en este pensamiento, igualdad de importancia (Joly, 1992: 276).

Desde el origen, según Joly, el pensamiento alquímico consideró al azufre como fuego, pues los alquimistas griegos lo concibieron como un equivalente de este elemento. Además este fuego tenía un papel primordial según lo sugería el vocabulario. Así la palabra griega Theion significaba al mismo tiempo azufre y lo divino. Según este autor, cuando Pierre-Jean Fabre precisa que el azufre reside en todas las cosas y les aporta su perfección, detectamos una concepción estoica del principio fuego tal como Cicerón la evoca en De natura deorum, cuando cede la palabra al estoico Lucilius Balbus: "Todos los seres que se nutren y crecen contienen en ellos un calor sin el cual no podrían ni nutrirse ni crecer" y "la esencia del calor contiene en ella una fuerza que se extiende a través del mundo entero". Es por eso que el azufre es considerado como un fuego que produce la madurez (Joly, 1992: 277).

Estas mismas ideas aparecen en el texto de Monsalve: el azufre que reside en el mercurio o que se transmuta por el fuego en azogue y el azufre asociado al fuego.

\section{EL FIRMAMENTO Y LOS METALES}

Ya hemos visto, cuando hemos tratado la generación de los metales, cómo el firmamento (y su movimiento) era concebido como el generador general en la producción de los metales, el cual ejercía sobre la tierra, considerada como la materia sumisa, su acción generatriz.

Otra idea que circulaba en el siglo XVII en Europa y que encontramos, de cierta forma, en nuestros autores es la de la relación entre los astros y los metales. Tanto los 
filósofos de la Antigüedad como los alquimistas afirmaban que en la generación de los metales era necesaria la intervención del firmamento y creían en la existencia de una relación estrecha entre los planetas y los metales. El filósofo neoplatónico Proclo escribía ya entonces:

"El oro natural, la plata o cada uno de los metales, así como las otras substancias, son engendradas en la tierra bajo la influencia de ciertas divinidades celestes y de sus emanaciones. El Sol produce el oro, la Luna la plata, Saturno el plomo y Marte el fierro" (citado por Hutin, 1951: 75).

Los alquimistas distinguieron siete metales, dos perfectos o inalterables —oro y plata - y cinco imperfectos — cobre, hierro, estaño, plomo y mercurio (argen vivo) simbolizados respectivamente por Venus, Marte, Júpiter, Saturno y Mercurio. Durante la Edad Media esta idea cobró mucha importancia y se mantuvo en vigencia durante los siglos posteriores: El Berbüchlein (1505) recuerda las tradiciones según las cuales los astros rigen la formación de los metales. La plata crece bajo la influencia de la Luna. Y los filones son más o menos argentíferos según su situación en relación a la dirección "perfecta" marcada por la posición de la Luna. El mineral de oro, crece, por supuesto, bajo la influencia del Sol:

"Según la opinión de los sabios, el oro es engendrado de un azufre el más claro posible y bien purificado y rectificado en la tierra, bajo la acción del cielo, principalmente del sol, de manera que no contenga más ningún humor que pueda ser evaporado por el fuego [...]. El Berbüchlein explica igualmente el nacimiento de los minerales de cobre bajo la influencia del planeta Venus, el del fierro por la influencia de Marte, y el del plomo por la influencia de Saturno" (Eliade, 1977: 40) (5).

Si bien, como hemos visto, encontramos huellas de ciertas concepciones alquímicas o de la Antigüedad en Alonso Barba, el minero de Potosí se opone por el contrario a estas ideas sobre la influencia de los astros en el génesis de los metales. En su obra expone dos razones que las contradicen: primero, el descubrimiento en los montes de Bohemia de un octavo metal, el bismuto, que él considera entre el estaño y el plomo, siguiendo en esto a Agricola que fue el primero en distinguir el bismuto como metal particular y la ausencia de una correspondencia entre el número de planetas y el de los metales:

"Ni ser solamente siete los metales (cuando queramos atribuir algo a la subordinación y concordancia que entre ellos y los metales se imagina) es cosa cierta hoy, pues con los instrumentos visorios o de larga vista, se observan otros más. Véase el tratado de Galileo Galilei de los satélites de Júpiter, y se hallará el número y movimiento de estos planetas nuevos, advertido con observaciones muy curiosas" (Alonso Barba, 1992[1640], libro I, cap. XXII: 41-42).

(5) El Berbüchlein es un texto atribuido a Colbus Fribergieus y publicado en Augsburg en 1505. Se trata de un libro importante que da cuenta del conjunto de tradiciones mineras de finales de la Edad Media y que es citado por Agrícola, el gran médico y químico del siglo XVI, en su $D e R e$ Metallica (1530-1550). 
Al contrario que Alonso Barba, otro eclesiástico en el Virreinato del Perú, Bernabé Cobo, sostiene esta idea; así afirma a propósito de los minerales:

"Siete son las diferencias específicas en que si divide todo género de metales, conviene a saber: oro, plata, azogue, cobre, hierro, estaño y plomo; en la generación de cada uno de los cuales influye un planeta, comunicándole su fuerza y actividad cada a aquél metal con quien tiene más analogía y afinidad. El oro recibe del Sol, todas sus buenas cualidades que tiene, sobre la plata predomina la Luna; Mercurio cuya naturaleza es influir mudanza, tienen especial cuidado del azogue, y así entreambos son bulliciosos e inconstantes; al cobre asiste Venus; al hierro, Marte; al estaño, Júpiter, y finalmente al plomo, el pesado y frío Saturno" (Cobo, 1964: 136).

Como ya lo hemos señalado en otro trabajo, estas diferencias de apreciación en cuanto a la influencia de los astros sobre los metales, entre estos dos representantes de la Iglesia en el Perú pueden dejarnos perplejos. En realidad, no son sorprendentes. Cobo era un naturalista que poseía un conocimiento general sobre los minerales y, a pesar de haber recorrido algunas minas y haber residido en Oruro, no se especializó en el estudio de los mismos; al parecer no tuvo contacto con los grandes cambios científicos del siglo XVI. Por el contrario, Alonso Barba consagró su vida a las minas y a la metalurgia y estaba muy al día en la literatura que trataba de los fenómenos naturales, como lo demuestran sus referencias al bismuto de Agrícola y al Siderius Nuncius de Galileo (publicado en 1611) en el que recoge el resultado de sus estudios sobre los satélites de Júpiter (Salazar-Soler, 1997).

En Monsalve, no encontramos una referencia explícita a la correspondencia entre el número de planetas y los metales, salvo en el caso del sol y el oro. En este eclesiástico el sol aparece como el generador general de todas las cosas y por lo tanto de todos los metales; esta idea se presenta de la siguiente manera:

"El sol es pater omnias vicun ties [?], no solo de los que tienen ánima sensitiva, pero tambien de los que tienen ánima vegetativa, pues él es el que concu[rre] a la generasion de todas las cosas procedientes de alguna causa particular, y asi vemos lo del filosopho cumplido en la generasion de los hombres, pues solos homo generan homines, lo mismo es en la generasion de los yrasionables, y vejetables y lo mismo es [to]da la generasion y procesion de todos los metales, sin el qual no tienen ni pueden tener ser ni essensia. Que aunque es verdad, que todos los planetas como segundas causas producen, y engendran por particular virtud que Dios les dio, y comunicó, pero no produçen [in]mediate como el sol, sino secundariamente como planetas, porque el sol tiene fuersa y potensia [como] sol y juntamente como planeta, y asi como t[al] influye segun conviene como causa segunda, pero como sol no sólo influye sino cria, y de una cosa hase otra, sacando de una materia otras más [-]da y levanta, como se ve en el oro, el qual es engendrado del sol, pues por su potensia disponiendo todas cosas sacó de lo más asendrado, y subtil de la tierra el más perfecto metal que la tierra pudo producir y criar, porque 
[teni] endo la perfecion que debe tener por virtud de su influencia le hiso tan seco, y enjuto que le preservó de corupsion, y [lo] vemos que entre todos los demas metales, el oro es el que más [gene]rasion tiene, por ser incorupto, [...] el qual para avello /558r/ de engendrar el sol como poderosso en la generasion crio primero el asufre escogiendo la parte de tierra más bien dispuesta y ésta para engendrar de ella el asufre quasi de su misma especie, en lo que toca a su calor este asufre lo engendró de lo más perfecto y puro de la tierra, aunque como siempre [testado: do] el planeta anda acompañado de los astros instantaneamente que el sol engendra el asufre, los demas astros como teniendo invidia engendran ellos como el mismo [testado: sus malesas] asufre sus malesas, y asi no pueden salir los metales puros como debian, porque pretendieron violar la generasion y potensia tan levantada del sol, el qual siempre procura sacar sus obras perfectas puras y asendradas, sino fuesen mestruadas por los demas planetas que con sus influensias quieren obscureser las obras tan grandes del sol [...]" (Monsalve, 1617: fols. 557r-559r).

El texto de Monsalve merece varios comentarios. En primer lugar, detectamos las huellas del esquema aristotélico de las almas vegetativa y sensitiva y el esquema causal (causas secundarias, particular...) del Estagirita. En segundo lugar, encontramos en este texto una de las principales ideas alquímicas: la solidaridad entre los diferentes reinos de la naturaleza; animales, plantas y minerales poseen una misma semilla a partir de la cual se desarrollan. Para volver a la comparación con Fabre, encontramos también esta idea en el Manuscriptum ad Fridericum, expresada de la siguiente manera: "lo que se encuentra arriba es de la misma naturaleza que lo que se halla abajo". Y como el mismo Fabre lo explica no hace sino retormarla de la Tabula smaradigma atribuida a Hermes Trismegiste, texto al cual la literatura alquímica medieval se refiere constantemente y cuyo autor no es evidentemente el dios griego sino un filósofo árabe del siglo VI, Balinas, quien lo atribuye a su vez a Apolonio de Tiana, un neopitagórico tardío (Joly, 1992: 54-55).

En tercer lugar, aparece el Sol como "creador" de los metales y de todas las cosas vivientes y en ese sentido asociado a Dios, o mejor dicho bajo las órdenes de él, creador supremo:

"Con él (el sol) se engendran todas las cosas, con él se crian, con él se aumentan con él se produçen, por él son eternas, en especial en su giro, por él los campos florecen, los rios dan sus frutos, la mar da sus peses $\mathrm{y}$ todos los elementos hasen sus operasiones, pues sesando la virtud y potensia del sol sesaran los vivientes, pues por él vivimos, por él permanesemos y tienen todas las cosas vi[da] y ser, pues teniendole por su padre claro está quien a de dar modo en nuestro vivir, pues sin el orden suyo no tuvieramos los hombres polisia humana, y asi u[vie]ra grandes disturbios en nuestro vivir pues él cria la plata, el oro para que podamos suplir nuestras nes[esi]dades, él nos produçe quanto oy la tierra tiene [de] que vivimos, al qual se le deben dar gracias por el cuidado que guarda en cumplir lo que dios nuestro señor le ordinó para bien nuestro [...]" (Monsalve, 1617: fol. 559r ). 
En cuarto lugar, aparece la idea según la cual el oro es el más perfecto de los metales, los otros metales son producidos por la acción o mejor dicho la interferencia de los otros planetas en la obra solar. Así el oro es el único metal perfecto, el resto de metales son imperfectos.

Según las concepciones de la época, la perfección del oro no se debía únicamente a su relación con el sol, otra idea la explicaba: el oro era el único metal que había completado su ciclo de desarrollo en las entrañas de la tierra y de ahí provenía su nobleza. Encontramos las raíces de esta idea en la teoría embriológica de la Antigüedad, en la cual la mina era comparada al vientre de la madre tierra y el mineral era considerado como un embrión. Esta teoría sostiene que si nada entraba el proceso de gestación, todos los minerales se convierten con el tiempo en oro. La Naturaleza tiene como fín último producir oro; sin embargo, se ve constreñida a engendrar diversos metales ya que frecuentemente se ve confrontada a obstáculos que le impiden actuar regularmente, como tiene costumbre de hacer. Es por ello, dice Eliade, que debemos considerar el nacimiento de metales imperfectos como abortos o monstruos que ocurren sólo porque la naturaleza ha sido desviada de sus acciones (Eliade, 1977: 41). Los alquimistas retoman esta teoría de la metamorfosis de los metales y sostienen que la alquimia no hace sino acelerar el crecimiento de los metales, contribuir a la obra de la Naturaleza precipitando el ritmo del tiempo.

El oro es el único metal considerado como maduro. Los otros metales son "crudos" e "inmaduros". Esta misma concepción la encontramos en la historia de la medicina. La idea es constante desde la alquimia china, que considera que, como el oro es el más perfecto de los metales por su incorruptibilidad, un principio activo extraído del oro (el oro potable) puede constituir una panacea, es decir, un remedio para la inmortalidad.

\section{Alonso Barba recoge estas ideas en su Arte de los metales:}

"Y así aunque en la definición de metal le competa a la plata y plomo, como al oro, no se infiere de aquí su distinción específica, pues pueden ser como lo son, perfecto el oro e imperfectos los demás, dentro de la misma especie de metal: como lo es el niño respecto del varón perfecto, que aunque tiene la misma definición esencial, se puede perfeccionar el niño y participarla mejor. Las propiedades diferentes que en los metales se ven, estorban, pues son accidentes que acompañan al estado de su imperfección y se les puede quitar. Y la permanencia que parece tienen en su ser, o procede de la tardanza con que se crían y van mejorando, que no depende de la humana observancia, pues aún a los árboles y yerbas no les vemos crecer, aunque los conocemos crecidos, o de la codicia humana que antes de tiempo los arranca de sus vetas" (Alonso Barba, 1992[1640], libro I, cap. XX : 39).

Según esta teoría, dado que el metal requiere de un cierto tiempo de formación, la explotación debe esperar el momento oportuno, pues de lo contrario se puede destruir un criadero cuyo valor (mineral) sería mayor al cabo del tiempo de maduración:

"Varias, y de calidades muy diferentes son las cosas que juntamente con los metales cria la naturaleza en sus venas, o ya sean como abortos que 
la codicia humana ocasiona, sacando antes del debido tiempo de las entrañas de la tierra lo que sazonandose en ellas viniera a ser metal perfecto o ya superfluidas excrementicias de la generación de toda suerte de metales: medios minerales se llaman de ordinario; estos son, sales, alumbres, caparrosas, azufre, oropimente (...)" (Alonso Barba, 1992[1640], libro II, cap. V: 74; Amorós, 1963).

Otro eclesiástico del Virreinato del Perú, Antonio de la Calancha afirmaba por su parte que "el metal cortado de peña en Potosí, si este año no es la ley, dentro de cuatro crece y tiene todos los quilates" (Calancha de la, 1972: folio 745).

\section{LA ALQUIMIA, LA IGLESIA Y EL PODER}

Alonso Barba y Monsalve, no representan casos excepcionales de utilización de referencias alquímicas en sus escritos; el arte tuvo mucha difusión en la época entre los "científicos" y en general entre los interesados por la naturaleza. La Iglesia también mantuvo relaciones con la alquimia, y encontramos tanto entre los franciscanos como entre los dominicos varios y famosos alquimistas.

Mencionemos por ejemplo a Roger Bacon (circa 1210-circa 1292) quien fue una de las figuras más brillantes de su tiempo y además representa el primer ejemplo del alquimista perseguido por la iglesia y encarcelado por herejía (Aromatico, 1996: 102). Sus trabajos más conocidos son: Tractatus trium verborum, Breve brevarium, Speculum secretorum alchemiae, Verbum abbreviatum y el Speculum alchemiae. Este último fue impreso en latin y francés en el siglo XVI y en una traduccion inglesa, The mirror of alchemy, en 1597 (Roberts, 1994).

En la tradición española, destaca Arnaldo de Vilanova (1240-1311), célebre fraile médico catalán, astrólogo y alquimista, citado por nuestro Alonso Barba, autor del Rosarius philosophorum. Su obra, según Aromatico, fue quemada después de su muerte porque contenía una tendencia profética que había peligrosamente introducido la doctrina herética de Joaquim de Fiore. Según Hutin, la alquimia se revela en Vilanova bajo un aspecto más filosófico: él desarrolla la noción, que tomó prestada probablemente de la cábala, de Spiritus, que constituye el vehículo de influencia de los astros en el universo y por analogía el intermediario entre el alma y el cuerpo en el microcosmos humano (Hutin, 1951: 47; Haven, 1896, citado por Hutin).

La literatura alquímica que le ha sido atribuida, un corpus de 57 títulos, parece pertenecer a los siglos XIV y XV. Thorndike piensa que hay unos 5 ó 6 tratados de Arnaldo auténticos, los otros son espurios. La tradición de Arnaldo como alquímico reposa según Roberts en los textos lullianos, sus tratados parecen indicar que conocía poco de alquimia (Roberts, 1994).

El Rosarius philosophorum, dedicado al cardenal Orsini, es el más famoso y el más largo de los tratados alquímicos de Arnaldo. Los otros trabajos son relativamente breves y dan instrucciones prácticas. El Rosarius tiene dos partes: téorica y práctica, una división popular en la época, como hemos dicho y similar a la del Arte de los metales. Encontramos en este autor, la creencia en la teoría de los dos elementos: azufremercurio, pero Arnaldo sostenía que el mercurio era el más importante de los dos, pues 
contenía su propio mercurio interno. Por otra parte sabemos que Vilanova comparaba el trabajo alquímico con la concepción, nacimiento, crucifición y resurreción de Cristo (Roberts, 1994: 37-38).

Vilanova, va a inspirar a dos otros grandes alquimistas franciscanos, el mayorquí Raymundo Lullio (1235-1315) y Jean de Rupescisa, autor de De la quintessence (6). Ambos autores forman parte de las referencias citadas por Alonso Barba en su Arte de los metales. Según historiadores recientes, los tratados alquímicos del primero habrían sido apócrifos (Hutin, 1951: 47). Roberts afirma que en trabajos auténticamente suyos, Lullio se muestra desfavorable e incluso condena a la alquimia y no cree en la transmutación. Sin embargo como sucede con Avicena, esto no impide que se le atribuyan trabajos alquímicos, incluso si ninguno aparece en la lista de los escritos realizados entre 1311 y 1314 . Lullio no fue considerado como alquimista sino hasta mucho después de su muerte, alrededor de los años 1370 (Roberts, 1994: 38-40). En cuanto a Rupescisa, murió hacia mediados del siglo XIV, condenado por numerosas profecías que estaban presentes en sus obras.

Con respecto a la orden dominica, durante la Edad Media, se decía que Santo Domingo, practicando la alquimia, había obtenido la piedra filosofal y había transmitido el secreto a Alberto Magno (1193-1280), alquimista reputado (Aromatico, 1996: 103), citado numerosas veces por Alonso Barba. Según Hutin, Alberto Magno, se interesó en la alquimia desde un punto de vista científico y experimental. Se dice que Alberto visitó minas y minerales, y afirmaba que investigaba la transmutación de los alquímicos y que el arte era el que más cercanamente imitaba a la naturaleza. Aceptaba la teoría del azufre y el mercurio en la generación de los metales y parece haber considerado la transmutación como posible pero difícil, aunque declaraba que nunca había sido testigo de una transmutación exitosa. Sin embargo, tuvo una reputación como alquimista después de su muerte, y hacia mediados del siglo XIV es mencionado como el autor de un tratado alquímico, el Alkimia minor. Cerca de treinta tratados alquímicos le son atribuidos; los cuales datan en su mayoría de los siglos XIV y XV. El Libellus de alchimia, conocido también como Semita recta es el más conocido (Roberts, 1994: 31-33).

Su discípulo, Tomás de Aquino (1225-1274), contrariamente a la leyenda según Hutin, no cultivó el arte sagrado. Sin embargo, consideraba la alquimia como una ciencia perfectamente lícita, siempre y cuando no abordara el campo mágico (Hutin, 1951: 46-47; Tomás de Aquino, Suma teológica, II, LXXVII, art. 2).

El nombre del papa Juan XXII está íntimamente ligado a la historia de la alquimia del siglo XIV. La alquimia no presentó en todas las épocas los mismos aspectos; ciertos espiritualistas le dieron un contenido muy particular, eminentemente simbólico asociado a una metafísica de carácter idealista, que dejaba las puertas abiertas a la especulación y a la experiencia interior (García Font, 1976).

A principios del siglo XIV, la oposición a la alquimia no pasaba del estado de críticas dispersas. Así Juan XXII en su bula Spondent quas non exhibent (1317), dirige

(6) Incluso si en el caso de Lullio existe una discusión acerca de si abrazó el gran arte o no, pues en parte de sus escritos aparece una crítica a la alquimia. Ver para la obra de Lullio: García Font, 1976: cap. V. 
ese tipo de ataques a los adeptos. Reprocha a los "infelices alquimistas" sus vanas promesas. La verdad les escapa y entonces ellos la inventan. Se atribuyen facultades y poderes que no tienen y disimulan sus imposturas bajo una logorrea fabulosa; a fin de cuentas, hacen pasar por oro y plata, gracias a sus artificios engañosos, metales que no son ni lo uno ni lo otro. La imprudencia es tal que llegan a veces a acuñar monedas falsas. Todos aquellos que se dedicaban a la fabricación del oro alquímico debían ser considerados como hombres falaces, sin honor; y debían ser castigados (García Font, 1976: 188-189; Ganzemüller, 1974).

Al parecer, la animosidad del papa se debió a que en su afán por conseguir dinero para lanzar una cruzada, el pontífice sucumbió a la tentación del horno y sus experiencias le costaron muy caro sin obtener resultado alguno. Por otro lado, sabemos por Nicolás Eymerich, que Juan XXII organizó cierto día un encuentro entre los adeptos al arte y sus opositores para zanjar la discusión sobre la materia. Fue luego del fracaso de los primeros que el papa publicó la bula (García Font, 1976: 189). Sabemos sin embargo, que en 1330, años después de la promulgación de la bula, el papa solicitó a su médico Geofroy des Isnards, obispo de Cavaillon, un alambique para fabricar alcohol y realizar una “obra misteriosa” destinada a su uso personal (García Font, 1976: 189; Ganzemüller, 1974).

Según Puerto Sarmiento, hubieron suspicacias de los inquisidores que, desde el siglo XIV contemplaron a los alquimistas como posibles reos del delito de herejía "porque cuando no consiguen los descubrimientos que desean acuden luego al diablo, sacrificándole víctimas, con invocaciones tácitas o expresas" (Eymeric, s.f.: 103, citado por Puerto Sarmiento, 1982: 254).

Cabe agregar, que hubieron obras, que intentaron hacer un acercamiento entre la alquimia y el cristianismo. Este es el caso por ejemplo de Fabre quien en su Alchymista Christianus (1632) establece una serie de correspondencias entre los sacramentos y las operaciones químicas: la calcinación simboliza la penitencia, el fuego y el agua representan el bautizo, la piedra filosofal, la eucaristía. De la misma manera, los alquimistas representan los sacerdotes, el espíritu del mercurio simboliza los ángeles, la tierra pura la Virgen María mientras que la sal es el símbolo de Cristo. El mercurio (es decir la materia primera de la piedra filosofal) fue considerado como representante de Dios. De manera general, la transmutación de los metales, considerada como una purificación, fue, en algunos casos, relacionada con la redención por la cual Cristo purificó a la humanidad de todos sus pecados (Joly, 1992: 43). Quizás este tipo de literatura inspiró a nuestros tratadistas en el Perú.

Además nos dice Puerto Sarmiento, las teorías alquímicas que podían entrar en confrontación con las de la Iglesia - como son la transmutación que se opone en parte al creacionismo y la de que la ciencia estagírica es revelada directamente por la Suprema Inteligencia al laborante - fueron mimetizadas y sometidas al dogma imperante. Así, algunos alquimistas afirmaban por ejemplo que los metales impuros eran obra de Dios, al igual que el resto de las criaturas, pero que la naturaleza se encargaba de transmutarlos en metales perfectos, oro y plata, porque esa era la voluntad divina y que el alquimista, al acelerar en su laboratorio esa transformación, no hacía sino cumplir la voluntad divina. Puerto Sarmiento afirma que los alquimistas sostenían también que el arte 
alquímico era una gracia que Dios concedía al laborante por medio de un santo en recompensa de su vida ejemplar; de tal forma que los principios alquímicos pudieran ser defendidos con relativa tranquilidad no sólo por hombres de ciencia sino también por clérigos y jerarquías eclesiásticas (Puerto Sarmiento, 1982: 256).

No solamente la Iglesia mantuvo relaciones con la alquimia; según Joly, el interés por la alquimia también puede medirse en la moda entre los grandes de Europa, en particular en Alemania y en Escandinavia, de invitar a los alquimistas a la corte; el gusto desinteresado por el desarrollo del saber no era sin duda el único motivo de esta hospitalidad. Intereses económicos movieron la curiosidad de reyes. Tampoco hay que olvidar que, como lo afirma Lain Entralgo, mecánica y alquimia son los dos grandes paradigmas científicos de los siglos XVI Y XVII. Entre los interesados por el arte podemos citar a, en Praga, Rodolfo II (1552-1612) y Fernando III (1608-1657); Cristina de Suecia (1626-1689), Fréderic de Saxe-Gotha (1616-1691) y su hermano Christian von Eisenberg (1635-1707), pero también Felipe II (1527-1598) rey de España y Elisabeth (1533-1603) reina de Inglaterra (Joly, 1992: 25) (7).

\section{SACERDOTES ALQUÍMICOS}

Como ya hemos señalado en trabajos anteriores, la teoría que emana del manual de Alonso Barba es el resultado de una combinación particular de varias interpretaciones inspiradas por la naturaleza andina y en concreto por la minería. Algunas de las ideas que encontramos en su manual, y que hemos discutido en este texto, tienen sus raíces en la Antigüedad. Son numerosas las referencias a autores clásicos: Empédocles, Platón, Aristóteles, Calístenes, Dioscórides, Lucrecio, Plinio, Galeno... Pero detectamos también en su obra el peso de otras "autoridades" como por ejemplo los filósofos árabes, tales como Avicena y Al Razi a quienes llama "lumbreras". Encontramos además a la filosofía medieval cristiana representada por Alberto Magno. De igual manera, los filósofos alquimistas catalanes de los siglos XIII-XIV, como Lullio (a quien designa como el "fenix de las ciencias") o Arnaldo de Vilanova son constantemente citados por nuestro tratadista. Por último, hallamos en el Arte de los metales, referencias a autores que llamamos y que el propio Alonso Barba llama "modernos": Bracesco, Cardano, Galileo, Paracelso, Porta y Basilio Valentino. No olvidemos por supuesto, las menciones a la autoridad en la materia, el tratadista alemán Georg Bauer - Agrícola - autor del Re Metallica (1530) (Salazar-Soler, 1997; Salazar-Soler, 2000: 350; Alonso Barba, 1992[1640], libro I, cap. XII, 23 y libro I cap. VII, 16).

Cuando se trata de exponer determinadas teorías ( $c f$. la generación de los metales o las "causas" de los metales) las referencias a tradiciones diversas aparecen sucedáneamente:

"En esto se funda la opinión de Calisthenes, de Alberto Magno, y de otro, que dicen hay una especie de metal perfecta, que es el Oro, y que los

(7) Van Lennep (1984) relata las aventuras alquímicas en las cortes de los príncipes de Europa; las transmutaciones eran objeto de una acuñación de medallas de oro conmemorativas, ciertas de las cuales son presentadas como hechas en oro alquímico (Entralgo, 1978; Puerto Sarmiento, 1982). 
demás metales, son sus incoaciones, ò principios, de donde les viene la facilidad de reducirse à su perfección, y poder convertirse en Oro todos" (Alonso Barba, 1992[1640], libro I, cap. XX: 38; Salazar-Soler, 2000: $351)$.

Es como si se tratara de la presentación de un paradigma de lo que se "sabe" que está compuesto de varias interpretaciones o más bien de fragmentos de diversas tradiciones culturales. La experiencia del propio Alonso Barba y el saber indígena son los otros componentes de la explicación que presenta el autor.

Detengámonos en la alquimia, que es el tema que nos ocupa y veamos cuál es el peso de esta tradición en sus explicaciones, cómo a cita a los autores alquímicos y su posición respecto a las teorías del arte. Al igual que los autores antiguos, los alquimistas aparecen a veces evocados no individualmente sino de manera genérica. Tomemos el ejemplo de la generación de los metales. Alonso Barba empieza exponiendo la teoría de los clásicos para luego presentar la de los alquimistas diciendo:

"Los Alquimistas (odioso nombre por la multitud de ignorantes, que con embustes lo han desacreditado) con más profunda, y práctica Filosophia, haciendo anatomía de los mixtos de la naturaleza, reduciendolos à sus primeros principios, discurren en la materia de los metales de esta manera" (Alonso Barba, 1992[1640], libro I, cap. XVIII: 34).

En algunas ocasiones, no aparece explícitamente el nombre de alquimistas pero el tratadista deja entender que se trata de ellos, como cuando define y describe el azufre y presenta la teoría de éstos:

"Llamanlo los que tratan de la Filosofía secreta de los metales, semilla masculina, y primer agente de la naturaleza en su generación" (Alonso Barba, 1992[1640], libro I, cap. X: 19).

Así, los alquimistas forman parte de su bagaje intelectual y muchas de las ideas que Alonso Barba adopta o utiliza en la primera parte (que he llamado teórica) de su tratado provienen de la alquimia. Pero como dice Amorós, Alonso Barba acepta las teorías alquimistas y la transmutación de los metales no sólo a través de las referencias y las citas constantes a alquimistas de renombre, sino que su experiencia y su práctica cotidiana en las minas de Potosí, que expone en la segunda parte de su manual, le hacen asumir estas teorías (Amorós, 1963: 171). Daremos aquí los ejemplos citados por Amorós.

El primero se refiere al experimento de la precipitación del cobre a partir de una solución de cobre por hierro:

"Es ocular desengaño y prueba de la posibilidad de la transmutación de unos en otros, pues con ella (la caparrosa azul) disuelta en agua, sin más artificio, convierte en cobre fino i no sólo el hierro, sino también el plomo, el estaño y aun la plata hace decaer de sus quilates y la reduce a cobre."

En el segundo ejemplo, Alonso Barba —según Amorós- confunde la amalgamación con la transmutación: 
"También el azogue común se convierte en plata fina, cierta prueba de la posibilidad y verdad dicha, de que hay tantos testigos de vista en estas Provincias, que fuera temerario o arrogante el desmentirlos a todos."

El tercer ejemplo se refiere al beneficio de las minas de hierro:

"La parte que tiene de hierro, quemada con la de azufre, que también de ordinario los acompaña, se convierte en vitriolo o caparrosa verde; ésta después se transmuta en cobre fino ..."

"La caparrosa azul, como la que llaman piedra lipis, de admirable fuerza para convertir todos los metales en cobre" (Amorós, 1963: 171-172) (8).

Sobre el carácter de la relación de Alonso Barba con la alquimia, García Font nos dice que para él Alonso Barba

“no es un 'Hermético' y no estuvo seducido por las promesas de una medicina alquímica, sino que más bien es un técnico, un operativo, no discute la autoridad de los grandes autores de tratados sobre el Arte, sino que admite la posibilidad de transmutaciones, alega pruebas y declara conocer testigos."

Continúa diciendo que Alonso Barba

"utiliza concepciones alquímicas en la medida que le proporcionan una 'explicación' a ciertos fenómenos naturales, pero que se mantiene prudentemente al margen de ciertas especulaciones audaces concernientes a los secretos y los misterios 'en los que muchos dicen creer, y que muy pocos han experimentado",.

Así dice García Font:

"Para Luanco (autor de La alquimia en España, 1889), Barba es un alquimista teórico, por nuestra parte pensamos que fue antes que todo un metalurgista práctico, que poseía los conocimientos que se tenían comúnmente en la época y en su profesión” (García Font, 1976: 246-247).

Para nosotros Alonso Barba es un empirista, entendiendo por empirismo no un sinónimo de práctica, sino una manera de reflexionar, de explicar una realidad concreta, una experiencia (la de Charcas en este caso). Y es en este sentido que él utiliza los conceptos provenientes de la alquimia. Pero a nuestro modo de ver, nuestro autor toma de la tradición alquímica algo más: la manera de construir o elaborar una teoría a partir de fragmentos de pensamientos o de ideas de otros autores. Quizás esta manera de elaborar un texto no sea exclusiva de la alquimia, sino común a otras corrientes o tradiciones culturales. Esto queda por explorar. En lo que se refiere a la elaboración de textos en la tradición alquímica García Font nos dice:

(8) Amorós nos da enseguida el contexto científico respecto a las teorías sobre la precipitación del cobre, diciendo que fue tan sólo diez años después que Angelus Sala, un italiano de Vicenza que trabajó en Dresde y luego en Baviera y Austria, trató de probar que la precipitación del cobre a partir de una solución de vitriolo por hierro metálico no era debido a la transmutación del hierro en cobre, sino simplemente a la separación del cobre presente en el vitriolo. 
"En la alquimia, la autenticidad no deja de ser la excepción; lo que es muy significativo, pues, [...] los 'artesanos' se esforzaban precisamente en transformar en oro 'auténtico' lo que era metal impuro o inmaduro. Aparentemente, sucedía lo mismo con los textos, que pasaban de un copista a otro, con retoques o modificaciones, algunas veces sin el nombre del autor, ciertas veces revestidas de atribuciones diversas y raras. El copista podía permitirse tal o cual libertad. Sin embargo, el problema no se reducía sólo a colocarse bajo la protección de una autoridad reconocida. Otras circunstancias intervenían: la necesidad de formar un 'cuerpo', el error, y otros factores [...]" (García Font, 1976: 127; Salazar-Soler, 1997).

Ya hemos mencionado algunas de las ideas alquímicas que hemos encontrado en Miguel de Monsalve; a diferencia del caso de Alonso Barba estamos incapacitados para analizar el resto del cuerpo teórico de este autor pues no aparece en la obra que hemos estudiado.

\section{COMENTARIOS FINALES}

Preocupados por la formación de un corpus de conocimientos en la minería peruana y por su proceso de transmisión, hemos tratado de mostrar la importancia que tuvo la alquimia entre las teorías que circularon entre nuestros tratadistas del siglo XVII. Lo que parece reflejar la situación europea para los siglos XVI y XVII y no sólo en el campo minero, pues como dice Joly, el siglo XVI constituye en efecto una época privilegiada para el estudio de la alquimia en Europa. Esto lo apreciamos por ejemplo en la medicina, según lo que acota Thorndike, a partir de lo que él llama un renacimiento paracelsiano (Joly, 1992: 24).

Es interesante señalar la complejidad y lo mixto de un cuerpo téorico como la alquimia, en donde no sólo podemos distinguir varias tradiciones, tales como la griega, latina, o china, así como también el aporte árabe - fundamental en nuestro caso, como lo hemos señalado en la teoría de los dos elementos: mercurio y azufre-, sino que, como lo hemos mostrado, muchas de las ideas fueron desarrolladas por los alquimistas pero tienen raíces en la Antigüedad. Es así que las teorías o las explicaciones elaboradas por nuestros tratadistas son composiciones hechas a partir de fragmentos provenientes de diversas tradiciones culturales que en muchos casos eran ya construcciones mixtas.

Lo ecléctico de estos cuerpos teóricos, como la alquimia, y la misma manera de elaborar las teorías, permitieron a ciertos tratadistas que se trasladaron al Perú, como Alonso Barba, incorporar creencias y saberes prehispánicos, que normalmente hubieran sido condenados por la Iglesia, al cuerpo de conocimientos occidentales, tal como lo hemos señalado en un trabajo anterior (Salazar-Soler, 1997).

Por último quisiéramos subrayar, aunque no lo hayamos tratado aquí, la complejidad o multiplicidad de los personajes estudiados: eclesiásticos, señores de minas como en el caso de Alonso Barba, tratadistas, y además autores de otros escritos tales como "La reducción universal de todo el Piru, y demas Indias con otros muchos avisos, para el bien de los naturales dellas, y en aumento de las Reales Rentas, del fray Miguel de Monsalve". 


\section{Referencias citadas}

ALONSO BARBA, A., 1992[1640] - El arte de los metales, en que se enseña el verdadero beneficio de los de los de oro, y plata con azogue. El modo de fundirlos todos y como se han de refinar; y apartar unos de otros, 232p.; Madrid: CSIC.

AMORÓS, J. L., 1963 - Notas sobre la historia de la mineralogía y cristalografía. IV- La mineralogía española en la época del Barroco: Alonso Barba, Madrid. Boletín de la Real Sociedad Española de Historia Natural, 61: 167-186.

AROMATICO, A., 1996 - Alchimie, le grand secret, 144p.; Paris: Découvertes Gallimard.

BARNADAS, J., 1986-Alvaro Alonso Barba (1569-1662). Investigaciones sobre su vida yobra, 283p.; La Paz: Biblioteca Minera Boliviana.

CALANCHA, A. de la, 1972 - Crónicas Agustinianas del Perú por Antonio de la Calancha y Bernardo de Torres (1639-1653); Madrid: C.S.I.C., Biblioteca Missionalia hispánica.

COBO, B., 1964[1653] - Historia del Nuevo Mundo; Madrid: BAE.

ELIADE, M., 1977 - Forgerons et Alchimistes, 188p.; Paris: Champs Flammarion.

ENTRALGO, L., 1978 - Historia de la medicina; Barcelona.

EYMERIC, N., s.f. - Manual de Inquisidores; Barcelona.

FABRE, P. J.,1992 [1690] - Manuscriptum ad Fridericum. In: Rationalité de l'Alchimie au XVIIe siècle, 408p.; Paris: Vrin.

GANZEMÜLLER, B., 1974 - L'alchimie au Moyen-Age; Verviers.

GARCÍA FONT, J., 1976 - Histoire de l'Alchimie en Espagne, 369p.; Paris: Dervy-Livres, Histoire et Tradition.

HAVEN, M., 1896 - Arnauld de Villeneuve; Paris.

HUTIN, S., 1951-L'alchimie. Que sais-je ?, 126p.; Paris: Presse Universitaire de France.

JOLY, B., 1992 - Rationalité de l'Alchimie au XVIIe siècle, 408p.; Paris: Vrin.

MOLINA, C. de, 1989[1575] - Relación de las fábulas y ritos de los Ingas; Madrid: Col. Historia 16, Crónicas de América, 48.

MONSALVE, M., 1617 - Tratado y discursos echos por el padre frai Miguel de Monsalve, predicador general de la Orden de predicadores aserca de la generasion del azogue, y cómo procede del asufre, y de cómo el azogue es la quincta essensia del azufre, dirigidos al mui illustre señor el doctor Juan de Solorsano Pereira del consejo de su magestad y su oidor en la Real audiensia de los Reyes, y gobernador de Guancabelica por el rey Nuestro Señor, manuscrito, Biblioteca Nacional de Madrid, J57, fols. 557-561.

PUERTO SARMIENTO, F. J., 1982 - La alquimia española durante el siglo XVI. In: América y la España del siglo XVI: 253-272; Madrid: CSIC.

ROBERTS, G., 1994 - The mirror of alchemy. Alchemical ideas and images in manuscripts and books. From Antiquity to the seventeenth century, 128p.; Toronto: University of Toronto Press.

SALAZAR-SOLER, C., 1997 - Alvaro Alonso Barba: Teorías de la Antigüedad, alquimia y creencias prehispánicas en las Ciencias de la Tierra en el Nuevo Mundo. In: Entre dos mundos. Fronteras culturales y agentes mediadores: 269-296; Sevilla: CSIC.

SALAZAR-SOLER, C., 2000 - Plinio historiador de entonces, profeta de ahora. La Antigüedad y las Ciencias de la Tierra en el virreinato del Perú (siglo XVI e inicios del XVII). In: $L a$ formación de la cultura virreinal. 1. La etapa inicial: 345-374; Madrid/Frankfurt: Iberamericana/ Vervuert Verlag.

VAN LENNEP, J., 1984 - Alchimie. Contribution à l'histoire de l'art alchimique; Bruxelles. 


\section{Anexo}

[fol. 557r]

[Cruz]

Tratado y discursos echos por el padre frai Miguel de Monsalve, predicador general de la Orden de predicadores aserca de la generasion del azogue, y cómo procede del asufre, y de cómo el azogue es la quincta essensia del azufre, dirigidos al mui illustre señor el doctor Juan de Solorsano Pereira del consejo de su magestad y su oidor en la Real audiensia de los Reyes, y gobernador de Guancabelica por el rey Nuestro Señor.

Item. Conosiendo mui illustre señor el gran deseo de vuestra merced aserca del aprobechamiento real como tan leal vasallo de su magestad, quise haser algunos discursos aserca de la generasion del azogue y producion de la quincta essensia del mismo asufre, el qual se vera por mis rasones, ser el azogue la quincta essensia i virctud del azufre como se vera por la experiensia queriendola haser como la embio a vuestra merced, de la qual se conosera que es sierto y verdadero, y ser engendrado y producido (mediante el fuego) del asufre, y que de [é]l, como de causa universal, resiben los demas metales ser, como primera materia de su generasion como lo dije en mis rasones, y respuesta que a vuestra merced embie, lo qual hasta oy hombre nasido [no] a alcansado, sabido ni entendido que el azogue fuese humo del asufre, y que este azogue se pudiese convertir en asufre lo qual vuestra merced experimentará, y conosera que es asi como lo digo, y echará de ver vuestra merced que las cosas que yo digo son siertas y verdaderas como paresera /v/ por lo siguiente.

El sol es pater omnias vicun ties [?], no solo de los que tienen anima sensitiva, pero tambien de los que tienen anima vegetativa, pues él es el que concu[rre] a la generasion de todas las cosas procedientes de alguna causa particular, y asi vemos lo del filosopho cumplido en la generasion de los hombres, pues solus homo generan homines, lo mismo es en la generasion de los yrasionables, y vejetables y lo mismo es [to]da la generasion y procesion de todos los metales, sin el qual no tienen ni pueden tener ser ni essensia. Que aunque es verdad, que todos los planetas como segundas causas producen, y engendran por particular virtud que Dios les dio, y comunicó, pero no produçen [in]mediate como el sol, sino secundariamente como planetas, porque el sol tiene fuersa y potensia [como] sol y juntamente como planeta, y asi como t[al] influye segun conviene como causa segunda, pero como sol no sólo influye sino cria, y de una cosa hase otra, sacando de una materia otras mas [-] da y levanta, como se ve en el oro, el qual es engendrado del sol, pues por su potensia disponiendo todas cosas sacó de lo mas asendrado, y subtil de la tierra el mas perfecto metal que la tierra pudo producir y criar, porque [teni] endo la perfecion que debe tener por virtud de su influencia le hiso tan seco, y enjuto que le preservó de corupsion, y [lo] vemos que entre todos los demas metales, el oro es el que más [gene]rasion tiene, por ser incorupto, y siendo él engendrado de corupsion, le puso el planeta en tanta perfecion (qu[itan]do las causas de su corupsion) que podemos decir lo hiso este por no estar sujeto a corupcion el qual para avello /558r/ de engendrar el sol como poderosso en la generasion crio primero el asufre escogiendo la parte de tierra mas bien dispuesta y ésta para engendrar de ella el asufre quasi de su misma especie, en lo que toca a su calor este asufre lo engendró de lo más 
perfecto y puro de la tierra, aunque como siempre[testado:do] el planeta anda acompañado de los astros instantaneamente que el sol engendra el asufre, los demas astros como teniendo invidia engendran ellos como el mismo [testado: sus malesas] asufre sus malesas, y asi no pueden salir los metales puros como debian, porque pretendieron violar la generasion y potensia tan levantada del sol, el qual siempre procura sacar sus obras perfectas puras y asendradas, sino fuesen mestruadas por los demas planetas que con sus influensias quieren obscureser las obras tan grandes del sol, porque como los astros tienen nesesidad del sol, para con su calor influir y engendrar, y dar ser a las cosas que ellos crian, aumentan y producen como tienen nesesidad de él por su calor, porque sin él no pueden producir cosa perfecta, siempre lo acompañan por ser participantes en su generasion, y con esto aiudados del sol engendran segun la ocasion. Siendo como son echos por la potensia y virtud del dicho sol como segundas causas, y como tal a quien Dios dio semejante virtud obró tan grandes y tan marabillosas cosas dignas de la potensia del sol, por donde se echa de ver su virtud y potensia, su dominio, y actividad, y su disposision pues el influir por si propio sin aiuda de otros sino por si mesmo, en los hombres, en los animales, en las plantas, y finalmente en todo lo vegetable derrama /r/ su potensia, para que crien, aumenten, produsgan y conserven todas las cosas que por su potensia fueron criadas y aumentadas, puras, y levantadas entre todas las obras de los demas astros pues ninguna de ellas llega a las que el sol por sí obra, porque por sí el sol puede criar infundir y trasmutar consumir y aumentar lo qual no tienen los demas astros, porque para haser alguna [-] cosa segun su virtud y potensia tienen nesesidad de aiuda del sol, sin la qual no puede otra ninguna segunda causa por si sola engendrar, criar, o disponer sino es con aiuda del mismo sol. Con él se engendran todas las cosas, con él se crian, con él se aumentan con él se produçen, por él son eternas, en especial en su giro, por él los campos florecen, los rios dan sus frutos, la mar da sus peses y todos los elementos hasen sus operasiones, pues sesando la virtud y potensia del sol sesaran los vivientes, pues por él vivimos, por él permanesemos y tienen todas las cosas vi[da] y ser, pues teniendole por su padre claro está quien a de dar modo en nuestro vivir, pues sin el orden suyo no tuvieramos los hombres polisia humana, y asi u[vie]ra grandes disturbios en nuestro vivir pues él cria la plata, el oro para que podamos suplir nuestras nes[esi]dades, él nos produçe quanto oy la tierra tiene [de] que vivimos, al qual se le deben dar gracias por el cuidado que guarda en cumplir lo que dios nuestro señor le ordinó para bien nuestro, y asi él es que a i[n]g[en]drado de lo mas graso de la tierra el asufre como tengo dicho, y con el calor interior de la tierra y con sus rayos penetrantes de su calor viene a ensender /559r/este asufre y yendose ensendiendose asta el lugar donde llegó su potensia este asufre va quemandose y abrasandose sin tener respirasion porque si la tuviera todo se fuera en humo y de ninguna manera se quajara [interlineado: genero de; testado: quemado] azogue antes quedara todo el metal consumido quemado sin ninguna substansia ni ser de cosa alguna que el sol criase ni engendrase, pero como se serro la puerta a esta generasion no teniendo respirasion fue el fuego quemando el asufre y piedras y lugares donde con la fuersa del fuego alcansaba y este humo deste asufre metiendose en los poros de la tierra y piedras, alli se congelaba y transmutaba en azogue, y siendo mucho el cosimiento del asufre esta fuersa aver mucho que quemar, y durar mucho tiempo de donde con el grande inçendio se quemó mucho el azogue, el qual por la mucha violensia del fuego lo quemó y deshiso, y no sólo esto, pero convirtió 
el azogue en la misma color del fuego que es bermillon, quemando, abrasando y recosiendolo en lo interior de la tierra vino a arronjar de la grasa del metal gran suma de espuma, que al pareser parece azeite y no lo es sino grasa del asufre. La qual grasa engendrada y conglutinada embebe, y recoje en sí gran suma de azogue desecho y lo convirtió en una especie bermeja, lisa, y grasienta, la qual es causa de que no pueda salir el azogue por los poros de la senisa porque los poros se sierran de tal manera que por via ninguna dan lugar a que pueda salir el azogue por lo qual se viene a quemar y a consumir infinito, porque empapado en la senisa /v/ por la parte de dentro se convierte en plastas, y por la parte de fuera hase lo mismo por donde viendose atajados los beneficiadores, y que no tienen remedio para sacar el azogue lo pierden y destruien todas sus hasiendas sin tener remedio para remediallo.

Item. De más que el azogue como tengo dicho es engendrado del azufre, y despues que por transmutasion a tomado el ser del azogue dejando el del asufre (mediante el fuego), esle tan contrario al azogue el humo del asufre, que en la holla fundiendose ambos a dos materiales azogue, y asufre tiene tanto dominio el humo del asufre sobre el humo del azogue que lo quema deshase, y consume y anihila, y antes que salga a la caperusa llega lo que llega mui consumido, porque la grasa del asufre es incorupta y perpetua de manera que la grasa dicha no tiene corupsion ni la puede tener y para que se vea ser asi tomese un poco de aseite sacado del asufre, sin genero de otra mixtura porque si la tubiere se consumira luego, y ensiendase una mecha la qual siempre a de estar ensendida y jamas se consumira y esto se hallara asi como lo digo pues esta grasa del asufre dicha destruie, quema y asa al azogue y no tiene alguacil que asi le consu[ma] como el humo de asufre, luego es cosa averigua[da] que a de salir el azogue menoscabado y destruido del poder de su madre la grasa, pues por gran ventura se [es]capa el azogue que se escapa para la defensa de lo qual se echa la senisa en las ollas para que en ellas se de[sa]ga el humo del asufre y que no pueda salir con el [testado: la] azogue porque no lo destruie, porque como el [testado : asufre] azogue/560r/ [testado:no] tiene cuerpo abre camino para poder salir y ponerse en salvo, dejando al enemigo enserrado con lo qual se escapa el azogue y con la dicha salida deja abiertos los poros de la senisa, y por ellos en dejando de salir sale tambien el humo del asufre, pero no con tanta potensia como tenia en la olla aunque tiene mucha que al fin destruye todo quanto puede su grande malisia, pero en los hornos, que yo he dicho, e manifestado, no puede haser ningun daño, porque el azogue en saliendo se quajara, y quajado no tiene fuersa contra el humo del asufre el qual tiene en las caperusas porque alli no se puede enfriar, ni quajar el azogue hasta que se enfrie la caperusa, y asi siempre el humo del asufre y antimonio ira consumiendo el azogue y esto es sierto y no ai que dudar.

Demas que lleva el metal de azogue infinitas malesas en las quales va una que se llama antimonio que es mui peor que el demonio pues el humo suio destruie abrasa y quema el azogue, y es de manera que echandole a un poco de azogue otro tanto de antimonio y menos dentro de veinte y quatro horas lo consume y no se hallara ni escoria del; como si no lo ubieran echado ni tenido en su vida, desta manera hase el antimonio los efectos del dimonio con el azogue, lo mismo hase su humo, el qual consume al azogue, donde quiera que está hase lo mismo [testado: hase] su humo, asi en las caperusas como en las ollas, el quitar todos estos daños y dejar el azogue libre para que 
salga y se aprobechen del es la scientia, el beneficio verdadero esta [...] lla, ese es el que se a de guardar como una cosa mui preciossa.

Y para que vuestra merced eche de ver que lo que yo digo es sierto y verdadero de que se engendra el azogue del humo del asufre, y vea vuestra merced con los ojos, y palpe con las manos, por donde se conosera que sé y entiendo lo que digo y no hablo fabulas, y asi mandará vuestra merced tomar un poco de azogue como dos o tres onzas, o lo que más a vuestra merced le paresiere y echallo a en un baso de bidrio, como un brinquino [testado: vuestra merced], echarle a, vuestra merced, un poco de agua fuerte de dorar, y [testado: haya ?] cubrir todo el azogue, despues tapallo con un poco de sera de modo que de ninguna manera respire ni entre tambien aire, y a de estar asi quarenta horas, aunque a las veinte i quatro hase so efeto, pero para más abundansia, al cabo de las quales basiara vuestra merced el pomo en una escudilla de barro bed[ra]da o de bidrio, y sacara el azogue y el asufre echo pie[dra] el qual tiene un amarillo deslabado y que no tiene ni [tuvie]se efectos de asufre porque como es la quincta essencia del asufre, el qual fue congelado del humo no tiene la essencia deste asufre por esta transmutasion y por virtud del agua fuerte, deseca su humidad se transmuta en piedra asufre sacando [la] essensia fixa del asufre de donde fue transformado del mismo azogue y solo la essensia corporea y la de su color permanece[ra] de donde se conosera ser legitimo asufre, cosa que asta oy hombre nasido a sacado a lus sino yo que hasiendo infinitas esperiensias saque esta.

Item. Y la causa porque el agua fuerte no conv[ier]te todo el azogue en a asufre, es porque el azogue es denso y no tiene poros por donde comunicar la virtud del agua fuerte y asi la comunica a la parte exterior del azogue, y le consume la humidad de manera que queda echa piedra asufre como se [dijo] pero tanta veses le pueden echar agua fuerte que se se[que] toda la humidad del azogue y se convierta en piedra, e lo [qual ?] para que vuestra merced vea que no hablo de memoria, y vuestra merced aga[lo] y echara de ver lo que digo que es una cosa bien misteriosa y extraordinaria. De vuestra merced capellan [cruz] frai Miguel de Monsalve.

Biblioteca Nacional, Madrid, J57 fol, 557-561. 